\title{
DIRECT SOLUTION TO PROBLEMS OF OPEN CHANNEL FLOW FOR VERTICAL TRANSITIONS
}

\author{
By \\ Sobeih, M. F. ${ }^{1}$, Rashwan, I. M. H. ${ }^{2}$ \\ 1-Associ. Prof., Civil Engineering Dept., Faculty of Engineering, Minufiya University. \\ 2-Lecturer, Water Engineering Dept., Faculty of engineering, Tanta University.
}

\begin{abstract}
The vertical transition occurred in open channel when the bed goes up or down suddenly or gradually. Such problem could be solved using the specific energy equation. Since the specific energy is measured with respect to channel bed as the datum, a rise or a fall in the bed of the channel causes a decrease or an increase in specific energy.

The authors presents in this paper new equations for the solution of the vertical transition problems for rectangular open channels.

The specific energy in this paper takes a dimensionless form to make the solution of the problem easier. By using the new dimensionless equation, the solution of the two types of vertical transition problems (rise or fall) would be available if the flow through channel subcritical or supercritical. Thus, the new dimensionless equation became very simple in use. Also the new derived equations were used to solve the problem if the rise in bed was bigger than the critical rise (maximum rise in bed).

From the above it was evident that, if the height of rise in channel bed (hump) was increased further the maximum value and the specific energy held constant with the hump and the discharge would be decreased until the given specific energy was equal to the minimum specific energy corresponding to the new discharge, as the energy could be increased without outside affect. Also, the upstream water depth would be changed to a new value called $\overline{y_{1}}$.
\end{abstract}

Manuscript received from Dr. M.F. Sobeih

Accepted on : 16/9/2002

Engineering Research Journal Vol 25, No 4, 2002 Minufiya University, Faculty of

Engineering, Shebien El-Kom, Egypt, ISSN 1110-1180 


\section{INTTODU்CTION}

i+o,

$y$

The vertical transition problem can be easily solved by the specific energy equation. Bakhmettef [1], in 1912, was the first who introduced the concept of specific energy. Specific energy in a channel is defined as the energy per unite weight of water at any section of a channel measured with respect to the channel bottom as a datum, thus

$$
E=d \cdot \cos \theta+\frac{\alpha V^{2}}{2 g}
$$

in which $E$ is the specific energy; $d$ is the normal water depth; $\theta$ is the bed slope; $\alpha$ the energy coefficient; $V$ is the mean velocity; and $g$ is the acceleration due to gravity. Or, for a channel of small slope $\theta \cong 0.0$, thus $\cos \theta=1.0$ and assuming $\alpha \approx 1.0$

$$
E=y+\frac{V^{2}}{2 g}
$$

in which $y$ is the water depth.

Since $Q=A . V$ Equation (1) may be written as:

$$
E=y+\frac{Q^{2}}{2 g A^{2}}
$$

in which $Q$ is the discharge; and $A$ is water cross-sectional area.

When the depth of flow is plotted against the specific energy for a given channel section and discharge, a specific-energy curve is obtained Fig. (1).

The curve shows that, for a given specific energy, there are two possible water depths, the low stage $y_{1}$ and the high stage $y_{2}$. The low stage is called supercritical flow. The high stage is called subcritical flow. The two depths are called alternative water depths. If the discharge changes, the specific energy will be changed accordingly. It is means that for every discharge there is a special curve.

\section{Vertical Transition Problems:}

When the bed elevation of an open channel changes along the length, so a vertical transition is provided as a link between the original and the new channel. Vertical transitions may be a rise in bed or a falling sudden drop or gradual transition a long a short distance or a long one. The solution of the problem using the specific energy equation takes the following shape: (assuming, the channel is smooth and rigid i.e. $\mathrm{h}_{1}=0.0$ )

$$
\begin{gathered}
E_{1}=E_{2} \pm \Delta Z \\
y_{1}+\frac{Q^{2}}{2 g A_{1}{ }^{2}}=y_{2}+\frac{Q^{2}}{2 g A_{2}{ }^{2}} \pm \Delta Z
\end{gathered}
$$

in which $E_{1}$ is the specific energy at the upstream of the transition; $E_{2}$ is the specific energy at the downstream of the transition; $\Delta Z$ is the rise or falling in bed; $y_{1}$ is the water depth at the upstream of the transition; $y_{2}$ is the water depth at the downstream of the transition; $A_{1}$ is the water cross-sectional at the upstream section of the transition; and $A_{2}$ is the water cross-section at the downstream of the transition. So, for a rectangular section: 


$$
y_{1}+\frac{Q^{2}}{2 g\left(b y_{1}\right)^{2}}=y_{2}+\frac{Q^{2}}{2 g\left(b y_{2}\right)^{2}} \pm \Delta Z
$$

in which $b$ is the section breadth.

$$
\begin{array}{ll} 
& E_{1}=y_{2}+\frac{Q^{2}}{2 g b^{2} \cdot y_{2}{ }^{2}} \pm \Delta Z \\
\text { or: } & 1=\frac{y_{2}}{E_{1}}+\frac{Q^{2}}{2 g b^{2} E_{1} y_{2}{ }^{2}} \pm \frac{\Delta Z}{E_{1}}
\end{array}
$$

Putting dimensionless parameters $Q_{*}=\sqrt{\frac{Q^{2}}{2 g b^{2} E_{1}^{3}}}, \Delta Z_{*}=\Delta Z / E_{1}$, and $y_{*}=y_{2} / E_{1}$ the above equation takes the form:

$$
1=y_{*}+\frac{Q_{*}^{2}}{y_{*}^{2}} \pm \Delta Z_{*}
$$

in which $Q_{*}$ is a dimensionless discharge; $y_{*}$ is the dimensionless water depth; and $\Delta Z$ is the dimensionless rising or falling in a channel bed.

In the above equation the plus sign means a rise in bed (Fig. (2)) while the minus one means a falling in a channel bed.

The following are some problems that usually involved in the hydraulic design for the vertical transitions.

1. To estimate the size of rising just required to make the flow critical (which lead to a maximum rise case);

2. To predict the flow behavior after the transition when the transition is smaller than that of the maximum;

3. To predict the flow behavior after the transition as well as upstream the transition when the size of the rise is larger than that of the maximum size; and

4. To predict the flow behavior after the transition when the transition is due to a fall in the channel bed.

\section{Type I}

\section{Case of Rise in Bed (Hump):}

$$
\begin{gathered}
1=y_{*}+\frac{Q_{*}{ }^{2}}{y_{*}{ }^{2}}+\Delta Z_{*} \\
y_{*}{ }^{2}=y_{*}{ }^{3}+Q_{*}{ }^{2}+\Delta Z_{*} y_{*}{ }^{2} \\
Q_{*}{ }^{2}=y_{*}{ }^{2}-y_{*}{ }^{3}-\Delta Z_{*} y_{*}{ }^{2} \\
Q_{*}=y_{*} \sqrt{1-y_{*}-\Delta Z_{*}} \ldots \ldots . . .
\end{gathered}
$$

Equation (3) plots as shown in the Fig. (3).

If the value of the rise in bed (hump) is increased to a certain value $\Delta Z_{\text {* }_{\max } \text {, }}$, then the flow at downstream will be critical. To get the condition of maximum rise in bed differentiates the discharge to the depth and equate to the zero as:

$$
\frac{d Q_{*}}{d y_{*}}=y_{*}\left(\frac{1}{2}\right)\left(\frac{1}{\sqrt{1-y_{*}-\Delta Z_{*}}}\right)\left(-1-\frac{d Z_{*}}{d y_{*}}\right)+\sqrt{1-y_{*}-\Delta Z_{*}}=0.0
$$




$$
\begin{aligned}
& \frac{d Z_{*}}{d y_{*}}=0.0 \text { where } \Delta Z_{* \max .} \\
& \Delta Z_{*_{\max }}=1.0-1.5 y_{*_{c}} \ldots \ldots \ldots
\end{aligned}
$$

in which $\Delta Z_{\text {vmax. }_{\text {max }}}$ is the dimensionless critical size of rising in bed (maximum rise in bed); and $y_{* c}$ is the dimensionless critical water depth.

Substituting Equation (4) into Equation (3) it can be obtained:

$$
\begin{aligned}
Q_{* c} & =y_{* c} \sqrt{1-y_{* c}-1+1.5 y_{* c}} \\
Q_{* c}{ }^{2} & =\sqrt{0.5 y_{* c}{ }^{3} \ldots \ldots \ldots \ldots \ldots \ldots} \\
y_{* c} & =\sqrt[3]{2 Q_{* c}{ }^{2}} \ldots \ldots \ldots \ldots \ldots \ldots \ldots \ldots \ldots \ldots \ldots \ldots \ldots
\end{aligned}
$$

in which $Q_{* c}$ is the dimensionless critical discharge.

Equations 4 and 6 can be plotted as shown in Figs. (4) and (5).

\section{Demonstration of Proposed Method}

As stated before there are three cases of rise in bed according to the amount of rise in bed $\Delta Z_{*}$ :

The known variables are always $Q, b$, and $y_{l}$ and the unknown variables will be as stated in the problem. According to the known variables of the problem, firstly determine the critical rising in a channel bed $\Delta Z_{* \max }$.

Comparing between dimensionless rising in bed $\Delta \dot{Z}_{*}$ and the critical dimensionless rising in bed $\Delta Z_{\text {*max }}$.

- If $\Delta Z_{*}=\Delta Z_{* \max .}$ it will be case I.

- If $\Delta Z_{*}\left\langle\Delta Z_{\text {*max. }}\right.$ it will be case II.

- If $\Delta Z_{*}>\Delta Z_{\text {*max. }}$ it will be case III.

\section{Case I: $\left(\Delta Z_{*}=\Delta Z_{* \max .}\right)$}

The known variables are $Q, b$, and $y_{l}$ and the unknown variable is $\Delta Z_{*}=\Delta Z_{\text {*max. }}$.

To solve this problem compute the upstream specific energy $E_{1}=y_{1}+\frac{Q^{2}}{2 g b^{2} y_{1}{ }^{2}}$ and the value of dimensionless parameter $Q_{*}=\sqrt{\frac{Q^{2}}{2 g b^{2} E_{1}^{3}}}$. Then get $y_{*_{c}}=\sqrt[3]{2 Q_{*}^{2}}$.

Finally compute the unknown critical rise in bed in dimensionless shape:

$$
\Delta Z_{* \max .}=1.0-1.5 y_{* c}
$$

By using the values of $Q_{*}$ and $\Delta Z_{\text {*max. }}$ get $\Delta Z_{\text {max. }}$ and the critical downstream $y_{* 2 c}$ ， due to the fact that the flow is critical, from the following equations:

$$
\begin{aligned}
\Delta Z_{\max } & =\Delta Z_{* \max } / E_{1} \\
y_{2 c} & =y_{* 2 c} \cdot E_{1}
\end{aligned}
$$


in which $y_{* 2 c}$ is the dimensionless critical water depth at the downstream of the transition.

\section{Case II: $\left(\Delta Z_{*} \leqslant \Delta Z_{\text {*max }}\right)$}

The known variables are $Q, b, y_{1}$, and $\Delta Z$ and the unknown is $y_{2}$.

Compute the maximum rise in bed using the same steps as in casse $I$.

Check that $\Delta Z_{*}\left\langle\Delta Z_{* \max }\right.$.

By using the values of $Q_{*}$ and $\Delta Z_{*}$ get $y_{* 2}$ from Equation (3), where $y_{* 1}<y_{* 2}<y_{* c}$ if the flow is supercritical and $\left.y_{* 1}\right\rangle y_{* 2}>y_{* c}$ if the flow is subcritical.

From any of the two states of flow the downstream water depth can be calculate as following:

$$
y_{2}=y_{* 2} \times E_{1}
$$

in which $y_{* 2}$ is the dimensionless water depth at the downstream of the transition.

Case III: $\left.\left(\Delta Z_{*}\right\rangle \Delta Z_{\text {*max }}\right)$

If the height of the rise in the channel bed (hump) is increased further the maximum $\Delta Z_{\text {* max }}$, then in order to pass the same discharge the specific energy will have to be increased. In this case for the approaching subcritical flow tward the hump.required increase in the specific energy which will be provided by the rise in the depth of flow at section 1. For supercritical flow approaching the hump the depth of flow at section 1 will be reduced, thereby providing the required increased in the specific energy.

$$
\begin{gathered}
E_{1}^{\prime}=E_{2 c}+\Delta Z\left(>\Delta Z_{\max }\right) \\
y_{1}^{\prime}+\frac{Q^{2}}{2 g\left(b y_{1}^{\prime}\right)^{2}}=y_{2}+\frac{Q^{2}}{2 g\left(b y_{2}\right)^{2}}+\Delta Z
\end{gathered}
$$

in which: $y_{1}^{\prime}$ and $E_{1}^{\prime}$ are the affected water depth of flow and specific energy, respectively, on the upstream and $E_{2 c}$ is the specific energy at downstream critical section. However, if the specific energy held constant with the hump of height more than the above indicated limiting value (critical rise in bed), the discharge is decreased until the given specific energy is equal to the minimum specific energy corresponding to the new discharge, as known that the energy cannot be increased without outside affecting.

Known are $Q, b, y_{l}$, and $\Delta Z$ and the unknown which are $y_{2 c}, \bar{Q}$ and $\overline{y_{1}}$.

Compute the maximum rise in bed using the same steps as in the case I.

Check that $\left.\Delta Z_{*}\right\rangle \Delta Z_{\text {*max. }}$ and then computes the following items as follows:

$$
\begin{gathered}
\overline{y_{* c}}=\frac{2}{3}\left(1.0-\Delta Z_{*}\right) \\
\overline{y_{2 c}}=\overline{y_{* c}} \times E_{1} \\
\overline{Q_{*}}=\sqrt{0.5\left(\overline{y_{* c}}\right)^{3}}
\end{gathered}
$$

The new dischärge is then:

$$
\bar{Q}=\sqrt{2 g b^{2} E_{1}^{3}\left(\overline{Q_{*}}\right)^{2}}
$$

The new upstream water depth is calculated from the following equations:

$$
\overline{Q_{*}}=\overline{y_{* 1}} \sqrt{1-\overline{y_{* 1}}-\Delta Z_{*}}
$$




\section{Type II}

$$
\overline{y_{1}}=\overline{y_{*}} \times E_{1}
$$

\section{Case of having a depression in Bed (Sump):}

The known variables are $Q, b, y_{l}$, and $\Delta Z$ and the unknown variable is $\mathrm{y}_{2}$.

To solve this problem computes the following parameters: $E_{1}, Q_{*}, \Delta \mathrm{Z}_{*}, y_{* 1}$ and $y_{* c}$.

Get the $y_{* 2}$ from the following equation:

$$
Q_{*}=y_{* 2} \sqrt{1-y_{* 2}+\Delta Z_{*}}
$$

We take $y_{* 2}<\mathrm{y}_{* 1}$ if the flow is supercritical.

Or we take $y_{* 2}>y_{* 1}$. if the flow is subcritical.

From any of the two states of flow the downstream water depth can be calculated as following:

$$
y_{2}=y_{* 2} \cdot E_{1}
$$

\section{CONCLUSIONS}

1-When the bed of a channel has a hump or a depression' it can be easily 'solved as a vertical transition problem by the proposed new dimensionless equations mentioned in the present research paper.

2-The rising in bed problem can be solved as a vertical transition problem with three cases according to the value of rising in bed $\Delta Z_{*}=\Delta Z_{\text {*max. }}, \Delta Z_{*}\left\langle\Delta Z_{\text {*inax: }}\right.$ and $\left.\Delta Z_{*}\right\rangle \Delta Z_{\text {*max }}$. If the height of rise in bed (hump) is increased further the maximum $\Delta Z_{* \max }$ and the specific energy held constant with the hump the discharge will be decreased until the given specific energy is equal to the minimum specific energy corresponding to the new discharge, because the energy cannot be increased without outside affecting. Also the upstream water depth will be changed to a new value $\overline{y_{1}}$.

3-The present research paper presented new easy dimensionless equations, which can be used to solve the falling in bed problem.

4-The proposed method presents new dimensionless discharge-depth relationships for rectangular section that facilitates a direct solution for all vertical transitional problems.

\section{REFERENCES}

1- Chow, V. T., "Open Channel Hydraulics" McGRAW-HILL; 1959.

2- El-Sheiwy, M. I. A., "Flow Characteristics Through Vertical Transitions", Master thesis, presented to Mansoura University, Faculty of Engineering, 1985.

3- Henderson, F. M, "Open Channel Flow", The Macmillan Co., New York, N.Y.

4- Modi, P. N. and Seth, S. M., "Hydraulics and Hydraulics Machines", New Delhi, 1968.

5- Nanndana Vitall, "Direct Solution to Problems of Open Channel Transitions", Journal of the Hydraulics Division, ASCE, Vol. 104, No. HY11, November, 1978.

6- Owais, T. M., "Open Channel Flow and Hydraulic Modeling", Lecture Notes, Civil Engineering Department, Faculty of Eng., El-Mansoura University, Egypt , 1976.

7- Rashwan, I. M. H.; "Flow Characteristics Through Horizontal Transitions", Master thesis, presented to Mansoura University, Faculty of Engineering, 1987. 
8- Zidan, A. R. A., Owais, T. M. and Rashwan, I. M. H. "Horizontal Transitions in Subcritical Flow", Mansoura Engineering Journal (MEJ) Vol. 15, No.1, June 1990.

\section{NOTATIONS}

The following symbols are used in this paper:

$A=$ the water cross-sectional area;

$A_{1} \quad=$ the water cross-sectional at the upstream of the transition;

$A_{2} \quad=$ the water cross-section at the downstream of the transition;

$b \quad=$ the section breadth;

$d \quad=$ the normal water depth;

$E \quad=$ the specific energy;

$E_{1} \quad=$ the specific energy at the upstream of the transition;

$E_{1}^{\prime} \quad=$ the affected water depth at the upstream of the transition;

$E_{2} \quad=$ the specific energy at the downstream of the transition;

$E_{2 c} \quad=$ the specific energy at the downstream critical section;

$g \quad=$ the acceleration due to gravity;

$Q \quad=$ the discharge;

$\bar{Q} \quad=$ new discharge upstream the transition;

$Q_{*} \quad=$ dimensionless discharge;

$\overline{Q_{*}} \quad=$ new dimensionless discharge at the upstream of the transition;

$V \quad=$ the main velocity;

$y=$ the water depth.

$y_{1}=$ the water depth at the upstream of the transition;

$y_{1}^{\prime} \quad=$ the affected water depth at the upstream of the transition;

$\overline{y_{1}} \quad=$ new water depth at the upstream of the transition;

$\overline{y_{* 1}}=$ new dimensionless water depth at the upstream of the transition;

$y_{2}=$ the water depth at the downstream of the transition;

$y_{*} \quad=$ dimensionless water depth;

$y_{*_{c}}=$ dimensionless critical depth of flow;

$\alpha=$ the energy coefficient;

$\theta \quad=$ the bed slope;

$\Delta Z \quad=$ the rise or falling in bed;

$\Delta Z_{*} \quad=$ dimensionless rising or falling in bed; and

$\Delta Z_{* \max }=$ maximum dimensionless rise in bed. 


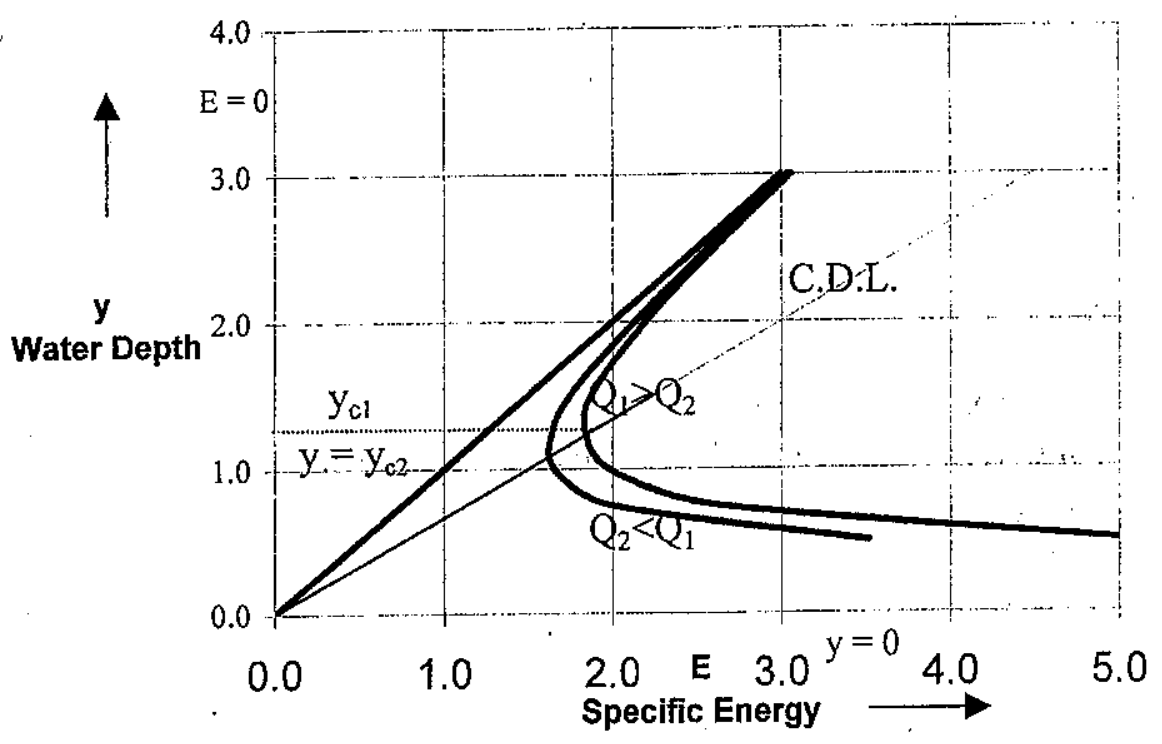

Fig. (1) Specific Energy Curve

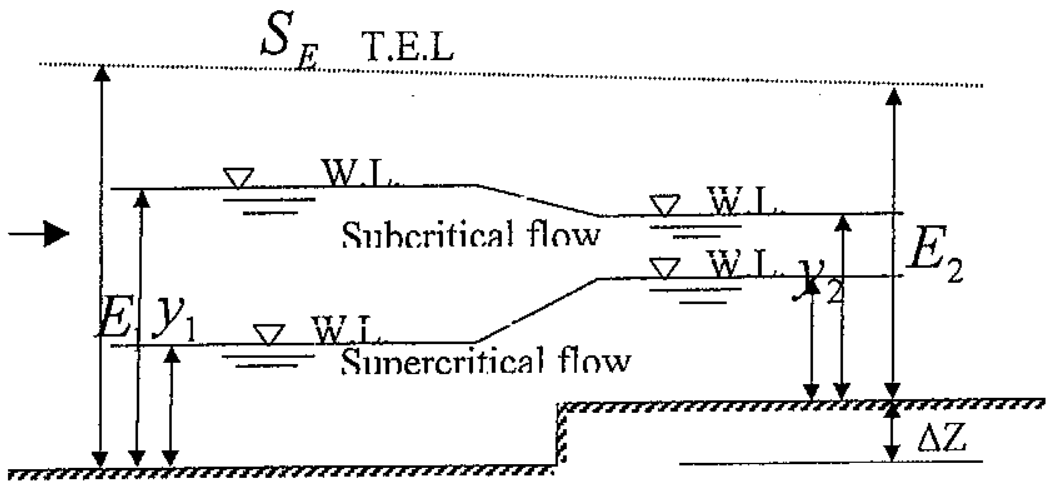

Flevation

Fig. (2) Definition Sketch for Vertical Transition (Rise in Bed) 


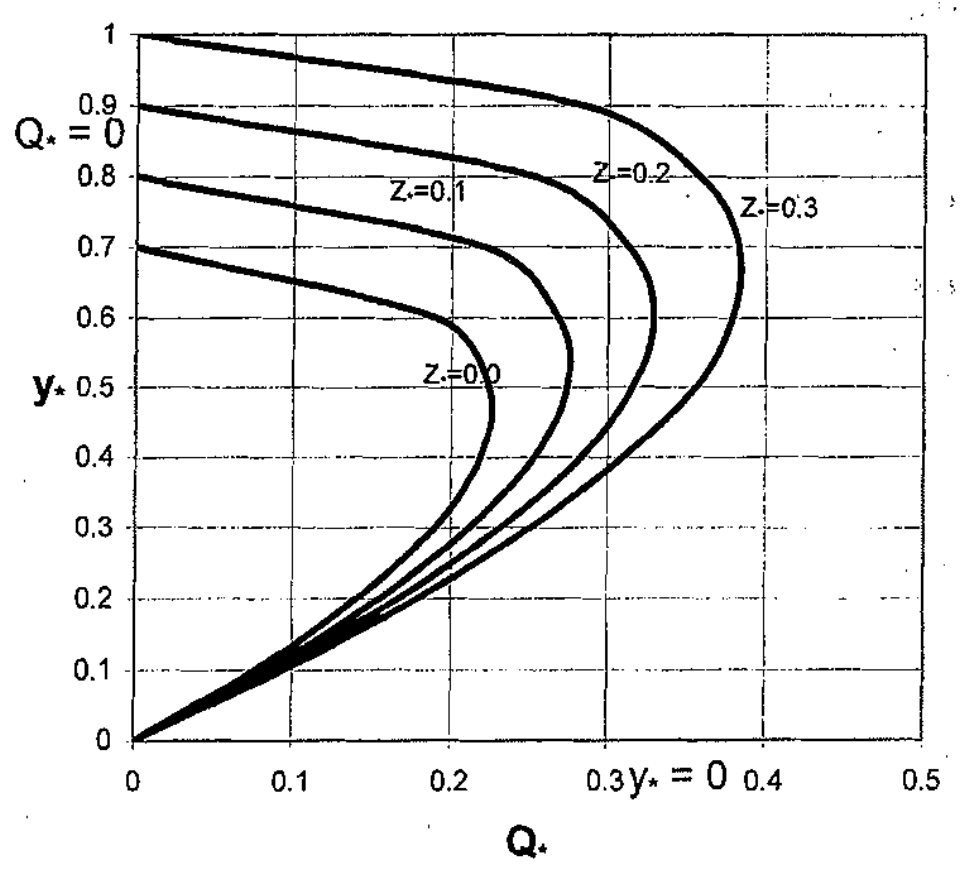

Fig. (3) Dimensionless water depth and Discharge Diagram

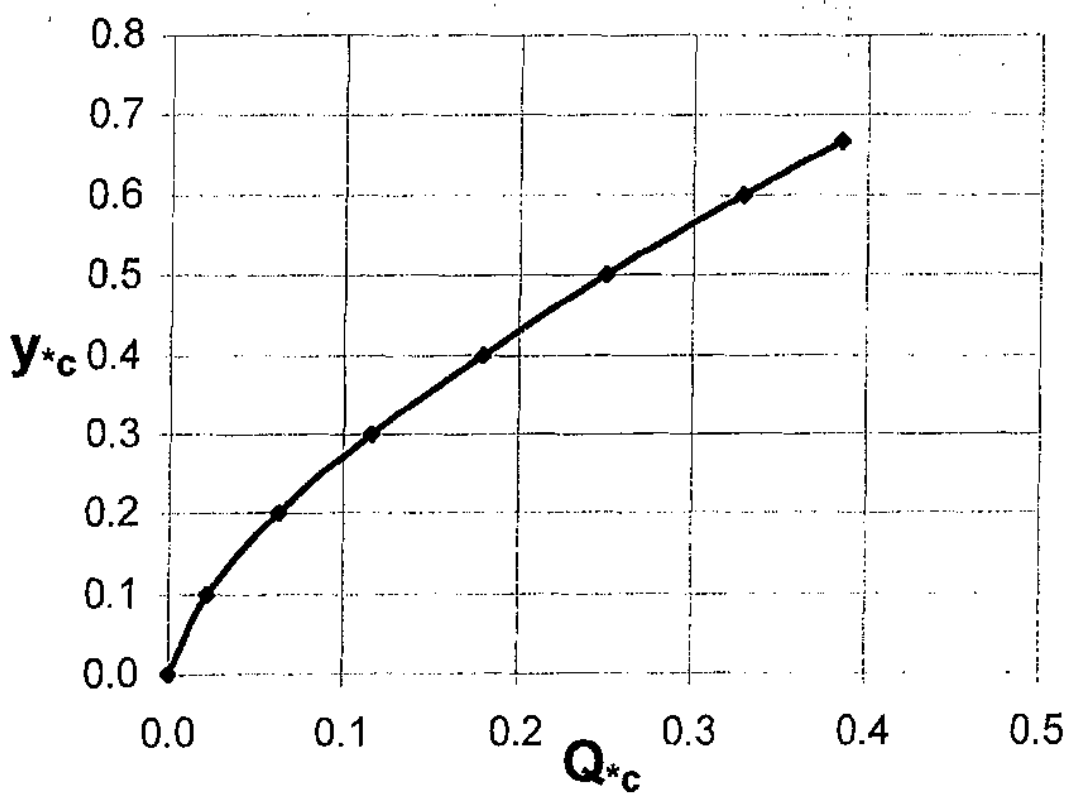

Fig. (4) Dimensionless Critical Water Depth and Critical Discharge Diagram. 


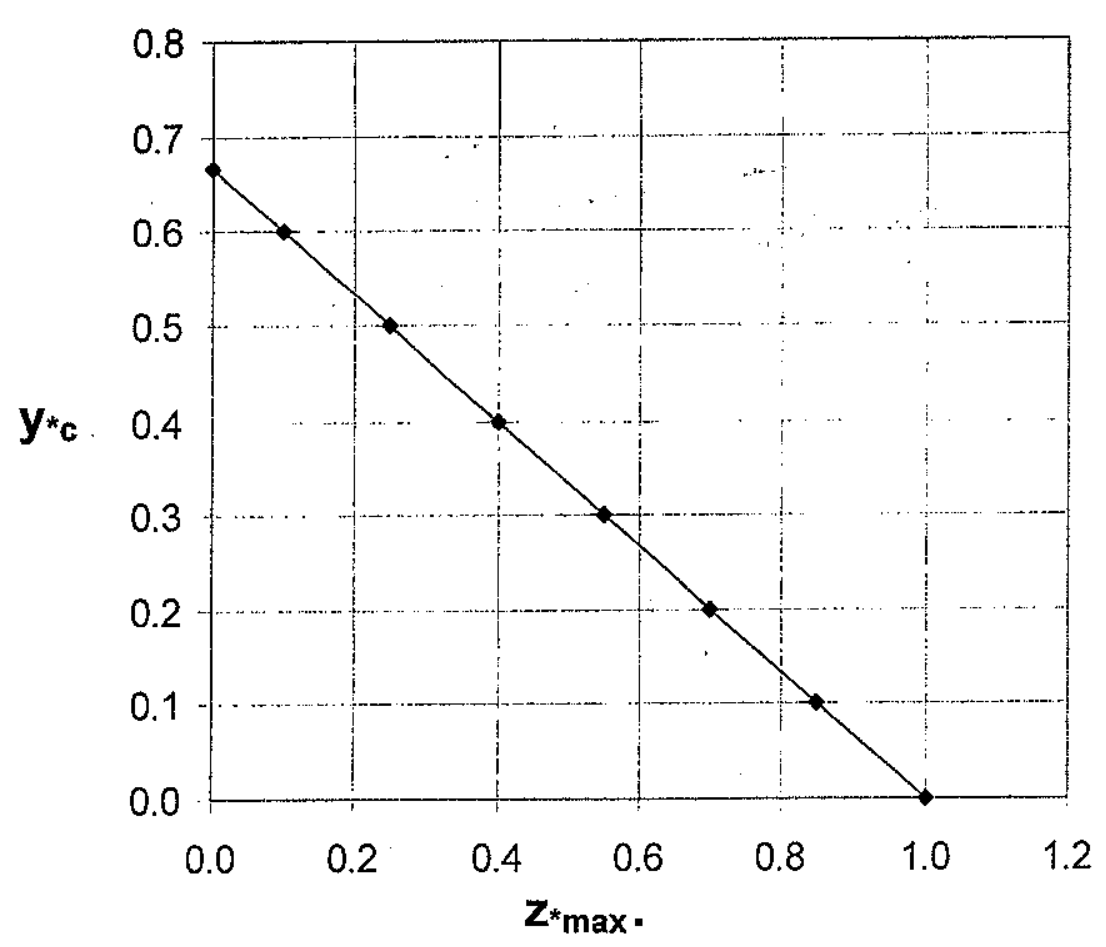

Fig. (5) Dimensionless Critical Water Depth and Dimensionless Maximum Critical Rise in Bed Diagram. 


\section{الحل المباثر لمسألة التغير الرأسى فى سريان القتوات المفتوحة أ.م.د/محمد محمد فؤاد صبيح د./إيراهيم محدد حسين رشوان}

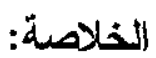

التغير الرأسى فى القتوات المفتوحة يحدث عثد تنير القاع بإرتفاعه المفاجىء أو

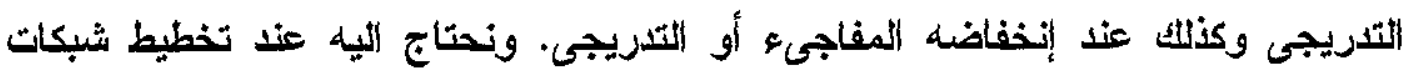
التلرع و المصارف وكنلك عند مداخل ومخارج بعض المنشآت الهيدروليكية.

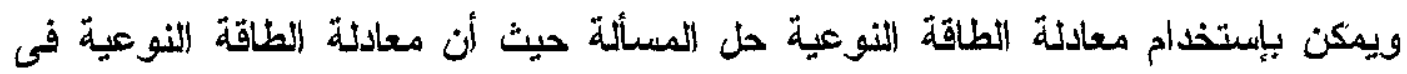

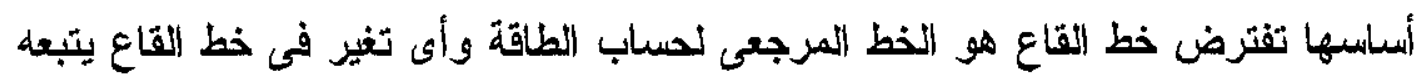
التغير فى الطاقة النوعية. ويهلف هذا البحث الى إيجاد "معادلة لاوحدات" لدل مسألة التغير الثأسى والتى تحدث كثيرا فى' القتوات المائية المفتوحة عند مختلف المنثآت المائية. وقد تم إستتناج "معادلات لاوحات" لحل كافة صور مسألة التغير الرأسى بنوعيه المختلفين

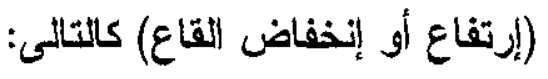

ا. إرتفاع القاع بقيمة أقل من القيمة العرجة تسبب تغير فى إرتفاع المياه فى الخلف مع ثبات مقار التصرف اللاخل إلى منطقة التثغير. r. إرتفاع القاع بقيمة تساوى القيمة الحرجة تسبب تغير في إرتفاع المياه فى الثلف

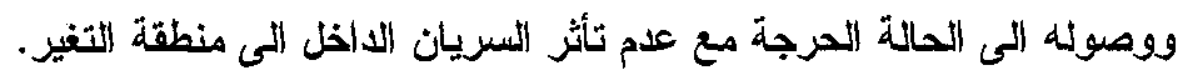
"ا. إرتفاع القاع بقيمة أكبر من القيمة الحرجة تسبب تنغير فى إرتفاع المياه فى الخلف التف مع نقص مقار التصرف اللادلل إلى منطقة التغير. ؛. إنخفاض القاع لحالثى السريان فوق وتحت الحرج لايؤثر على مقدار التصرف. 